\title{
Photolysis of diatomic molecules as a source of atoms in planetary exospheres ${ }^{\star}$
}

\author{
R. R. Valiev ${ }^{1,2}$, A. A. Berezhnoy ${ }^{3}$, I. S. Gritsenko ${ }^{4}$, B. S. Merzlikin ${ }^{5}$, V. N. Cherepanov ${ }^{4}$, T. Kurten ${ }^{1}$, and C. Wöhler ${ }^{6}$ \\ 1 University of Helsinki, Department of Chemistry, PO Box 55, A.I. Virtanens Plats 1, 00014 Helsinki, Finland \\ e-mail: valievrashid@gmail.com \\ 2 Research School of Chemistry and Applied Biomedical Sciences, Tomsk Polytechnic University, Lenin Avenue 30, \\ Tomsk 634050, Russia \\ 3 Sternberg Astronomical Institute, Moscow State University, 13, Universitetskij pr., 119234 Moscow, Russia \\ 4 Tomsk State University, 36 Lenin Avenue, 634050 Tomsk, Russia \\ 5 Tomsk State University of Control Systems and Radioelectronics, 40 Lenin Avenue, 634050 Tomsk, Russia \\ ${ }^{6}$ Image Analysis Group, Technical University of Dortmund, Otto-Hahn-Str. 4, 44227 Dortmund, Germany
}

Received 3 July 2019 / Accepted 24 July 2019

\begin{abstract}
We calculated the cross sections of photolysis of $\mathrm{OH}, \mathrm{LiO}, \mathrm{NaO}, \mathrm{KO}, \mathrm{HCl}, \mathrm{LiCl}, \mathrm{NaCl}, \mathrm{KCl}, \mathrm{HF}, \mathrm{LiF}, \mathrm{NaF}$, and $\mathrm{KF}$ molecules using quantum chemistry methods. The maximal values for photolysis cross sections of alkali metal monoxides are on the order of $10^{-18} \mathrm{~cm}^{2}$. The lifetimes of photolysis for quiet Sun at 1 astronomical unit are estimated as $2.0 \times 10^{5}, 28,5,14,2.1 \times 10^{5}, 225,42,52$, $2 \times 10^{6}, 35400,486$, and 30400 s for $\mathrm{OH}, \mathrm{LiO}, \mathrm{NaO}, \mathrm{KO}, \mathrm{HCl}, \mathrm{LiCl}, \mathrm{NaCl}, \mathrm{KCl}, \mathrm{HF}, \mathrm{LiF}, \mathrm{NaF}$, and $\mathrm{KF}$, respectively. We performed a comparison between values of photolysis lifetimes obtained in this work and in previous studies. Based on such a comparison, our estimations of photolysis lifetimes of $\mathrm{OH}, \mathrm{HCl}$, and $\mathrm{HF}$ have an accuracy of about a factor of 2 . We determined typical kinetic energies of main peaks of photolysis-generated metal atoms. Impact-produced $\mathrm{LiO}, \mathrm{NaO}, \mathrm{KO}, \mathrm{NaCl}$, and $\mathrm{KCl}$ molecules are destroyed in the lunar and Hermean exospheres almost completely during the first ballistic flight, while other considered molecules are more stable against destruction by photolysis.
\end{abstract}

Key words. meteorites, meteors, meteoroids - stars: kinematics and dynamics - molecular processes - molecular data radiation mechanisms: general - ultraviolet: planetary systems

\section{Introduction}

The photodissociation of diatomic molecules is an important source of atoms in various celestial objects. Comprehensive reviews of photodissociation cross sections of molecules of astrophysical interest have been published (Huebner et al. 1992; Huebner \& Mukherjee 2015; Heays et al. 2017). Simple molecules can be delivered to the exospheres of Mercury and the Moon during meteoroid bombardment (Berezhnoy \& Klumov 2008; Berezhnoy 2013). Volcanic eruptions are main sources of chlorides and fluorides of alkali elements in the atmosphere of Io (Schaefer \& Fegley 2005). Subsequent photolysis of alkali chlorides is an important source of $\mathrm{Na}$ and $\mathrm{K}$ atoms in the exosphere of Io (Moses et al. 2002).

Observations of emission lines of metal atoms in exospheres of bodies of the solar system have a long history. Atoms of $\mathrm{Na}$, $\mathrm{K}, \mathrm{Al}$, and $\mathrm{Fe}$ have been detected in the exosphere of Mercury (Cassidy et al. 2015; Bida \& Killen 2017). The content of Na and $\mathrm{K}$ atoms in the lunar exosphere was studied with the lunar orbiter, the Lunar Atmosphere and Dust Environment Explorer (LADEE; Colaprete 2016); Na atoms were also detected in the exospheres of Io and Europa (Brown \& Hill 1996; Mendillo et al. 2007). Metal atoms generated during photolysis of metal-containing species are generally hotter than those formed during chemical reactions

* Tables of the cross-sections are only available at the CDS via anonymous ftp to cdsarc.u-strasbg.fr $(130.79 .128 .5)$ or via http: //cdsarc.u-strasbg.fr/viz-bin/cat/J/A+A/633/A39 in the impact-produced clouds (Berezhnoy 2018). For example, high observed temperatures of $\mathrm{Al}$ and $\mathrm{Fe}$ atoms in the Hermean exosphere are explained by photolysis of Al-, and Fe-containing species (Bida \& Killen 2017).

$\mathrm{NaCl}$ and $\mathrm{KCl}$ molecules were detected in the circumstellar envelope IRC +10216 (Agúndez et al. 2012). $\mathrm{KCl}$ was tentatively detected in the atmosphere of Io (Moullet et al. 2013). $\mathrm{NaCl}$ and $\mathrm{KCl}$ may be also abundant at the surface of Mercury (Evans et al. 2015). Chlorides of alkali elements are expected to be present in cool dwarf atmospheres (Lodders 1999), in clouds of super-Earth atmospheres (Mbarek \& Kempton 2016), and in lunar volcanic gases (Renggli et al. 2017). Rotation-vibration line lists for considered diatomic molecules in their ground electronic states have been published for $\mathrm{NaCl}$ and $\mathrm{KCl}$ by Barton et al. (2014) and for $\mathrm{LiCl}$ and $\mathrm{LiF}$ by Bittner \& Bernath (2018), and the same transitions and others have been studied recently by Wan et al. (2015). HCl and HF molecules were detected in the coma of comet Churyumov-Gerasimenko (De Keyser et al. 2017; Dhooghe et al. 2017) and in interstellar medium (Indriolo et al. 2013; Monje et al. 2013), while $\mathrm{HCl}$ was also detected in the atmosphere of Venus (Sandor \& Clancy 2012). Detailed studies of $\mathrm{HCl}$ and $\mathrm{HF}$ photolysis are required for deeper understanding of chlorine and fluorine behavior in the interstellar medium (Acharyya \& Herbst 2017); HF absorption has been studied ab initio by Li et al. (2010) and Brown \& Hill (1996), and experimentally by Brown \& Hill (1996). The $\mathrm{OH}$ radical is one the main molecular species in the Universe and has been detected 
at the surface of on the Moon, in cometary atmospheres, and in many other objects (Litvak \& Sanin 2018). The OH radical is the most important oxidant in the Earth's troposphere, and both $\mathrm{OH}$ and $\mathrm{HCl}$ participate in ozone-depleting catalytic cycles in the stratosphere.

The main parameters of photolysis of species in planetary exospheres are photolysis lifetimes and kinetic energies of products of photolysis (Huebner et al. 1992). For an estimation of these parameters, knowledge of the wavelength dependence of the photolysis cross section of studied species is required. The ultraviolet-absorption cross sections for alkali halides such as $\mathrm{LiCl}, \mathrm{NaCl}$, and $\mathrm{KCl}$ were measured by Davidovits \& Brodhead (1967). The photodissociation cross section of $\mathrm{NaCl}$ was also measured by Silver et al. (1986). However, similar studies of alkali fluorides have not been performed yet. Based on experimental measurements of photodissociation cross sections, photolysis lifetimes of chlorides, bromides, and iodides of $\mathrm{Li}, \mathrm{Na}$, and K were estimated by Schaefer \& Fegley (2005). Alkali and chlorine photochemistry in the atmosphere of Io was studied in detail by Moses et al. (2002). Analysis of observations of Io's sodium exosphere during a solar eclipse performed by Grava et al. (2014) agrees with an estimation of the lifetime of $\mathrm{NaCl}$ photolysis carried out by Schaefer \& Fegley (2005). The photolysis lifetime of $\mathrm{OH}$ in the gas phase and on the surface of the Moon is an important parameter for correct modeling of the behavior of hydrogen-containing species on the Moon (Grumpe et al. 2019).

Photolysis cross sections of gas-phase molecules are usually obtained experimentally (Huebner et al. 1992). There are only a few papers devoted to theoretical studies of photolysis of diatomic molecules, especially $\mathrm{OH}$ (van Dishoeck \& Dalgarno 1983; Lee 1995) and $\mathrm{HCl}$ (van Dishoeck et al. 1982). Previously, we also developed the original quantum-chemical model to estimate the photolysis cross section of diatomic molecules and applied this applied this model to studies of photodissociation of $\mathrm{LiO}, \mathrm{NaO}, \mathrm{KO}, \mathrm{MgO}$, and $\mathrm{CaO}$ (Valiev et al. 2017). However, other important diatomic molecules such as alkali metal chlorides, bromides, and hydrides of $\mathrm{O}, \mathrm{F}$, and $\mathrm{Cl}$ were not considered by Valiev et al. (2017). The goal of this paper is to estimate photodissociation cross sections and photolysis lifetimes of diatomic molecules $\mathrm{OH}, \mathrm{HF}, \mathrm{LiF}, \mathrm{NaF}, \mathrm{KF}, \mathrm{HCl}, \mathrm{LiCl}, \mathrm{NaCl}$, and $\mathrm{KCl}$, and the energies of photolysis-generated $\mathrm{Li}, \mathrm{Na}, \mathrm{K}$, and $\mathrm{H}$ atoms using modern ab initio quantum-chemical codes and the improved model of Valiev et al. (2017). Also, we investigate the $\mathrm{LiO}, \mathrm{NaO}$ and $\mathrm{KO}$ molecules using the improved and corrected model because the saddle point method of integral evaluation was previously not correctly applied (Valiev et al. 2017). We consider the well-known molecules $\mathrm{OH}, \mathrm{HF}$, and $\mathrm{HCl}$ in order to estimate the accuracy of our model by comparing to our results with available experimental and theoretical studies. In the present paper all appeared integrals are calculated explicitly, analytically, or numerically with high accuracy. Knowledge of the parameters of photolysis of these molecules is important for investigations of the behavior of alkali elements in planetary exospheres, atmospheres of cool stars, exoplanets, and envelopes of evolved stars.

\section{Theory and quantum chemical model}

The description of our model and computational details of calculations are considered in this chapter. In the first subsection of theory the main formulas are described and the description of quamtum chemical methods is given in the second subsection.

\subsection{The theory}

The rate of photolysis $J$ of considered molecules by solar photons at $1 \mathrm{AU}$ from Sun can be written as

$J=\int_{0}^{\lambda_{\text {bind }}} \sigma(\lambda) \Phi(\lambda) \mathrm{d} \lambda$,

where $\sigma$ is the photolysis cross section, $\Phi$ is the unattenuated solar photon flux at $1 \mathrm{AU}$ heliocentric distance, and $\lambda_{\text {bind }}$ is the wavelength of photons corresponding to the binding energy including the vibrational zero-point correction (Huebner et al. 1992). The calculation of $J$ can be carried out numerically using the dataset of known values of photolysis cross sections and solar photons flux in the chosen region of electromagnetic spectrum.

Considering the laws of conservation of energy and momentum, the kinetic energy of metal atoms $E_{\text {kin } \_i}(\mathrm{Me})$ formed during photolysis of a metal diatomic molecule $\mathrm{Me}-\mathrm{X}$ (where $\mathrm{X}=\mathrm{O}, \mathrm{F}$, or $\mathrm{Cl}$ ) at $i$ th electronic transition can be calculated as

$E_{\mathrm{kin} \_i}(\mathrm{Me})=\frac{E\left(\lambda_{i}\right)-E\left(\lambda_{\text {bind }}\right)}{1+A_{r}(\mathrm{Me}) / A_{r}(\mathrm{X})}$,

where $E\left(\lambda_{i}\right)$ is the energy of photons corresponding to wavelength of maximal photolysis cross section of $i$ th electronic transition, $E\left(\lambda_{\text {bind }}\right)$ is the binding energy of the considered bound $\mathrm{Me}-\mathrm{X}$, and $A_{r}(\mathrm{Me})$ and $A_{r}(\mathrm{X})$ are the atomic masses of considered metal atom and atom X, respectively. Equation (2) is valid if photolysis-generated metal atoms are formed in the ground electronic state.

Photolysis cross sections for atmospheric gases are obtained mainly based on laboratory experiments (Huebner \& Mukherjee 2015), but the photolysis of $\mathrm{OH}$ (van Dishoeck \& Dalgarno 1983; Lee 1995; van Dishoeck et al. 1984), HF (Brown \& Balint-Kurti 2000), and $\mathrm{HCl}$ (Engin et al. 2012; Alexander et al. 1993; Lambert et al. 1998; Regan et al. 2000; Duhoo \& Pouilly 1995) were also studied theoretically. Among considered diatomic molecules, the photolysis of $\mathrm{NaO}$ was studied experimentally (Self \& Plane 2002), and there are also experimental values of photolysis lifetimes for $\mathrm{OH}, \mathrm{HF}, \mathrm{HCl}, \mathrm{LiCl}, \mathrm{NaCl}$, and $\mathrm{KCl}$ (Huebner \& Mukherjee 2015; Schaefer \& Fegley 2005).

Diatomic molecules can have bound and unbound electronic states (Valiev et al. 2016; Langhoff et al. 1986). For the case of photolysis reactions after absorption of a photon, these molecules appear in excited vibronic states of the continuous spectrum. The photolysis cross section $(\sigma)$ for such transitions can be calculated as (Riess 1972; Herzberg 1989)

$\sigma(E)=\frac{4 \pi^{2}}{3 c} E\left|\left\langle\left\langle\Psi_{f}(r, R)|\boldsymbol{d}| \Psi_{i}(r, R)\right\rangle\right\rangle\right|^{2}$,

where $\Psi_{f}(r, R)$ is the vibronic wave function of a molecule at the final excited state of continuous spectrum of energy, $\Psi_{i}(r, R)$ is the vibronic wave function at the initial state of the molecule at the bound state of discrete spectrum of energy, $E$ is the energy difference between initial and final states, $\boldsymbol{d}$ is the dipole moment operator of the molecule, $c$ is the speed of light, $R$ is the nuclear coordinate, and $r$ is the electronic coordinate. In this section and throughout the paper all formulas are written in the atomic unit system.

When the adiabatic approximation is fulfilled, the initial and final wave functions can be written in the form

$\Psi_{f}(r, R)=\psi_{f}(r, R) \cdot \chi_{\text {cont }}(R)$,

$\Psi_{i}(r, R)=\psi_{i}(r, R) \cdot \chi_{\text {in }}(R)$. 


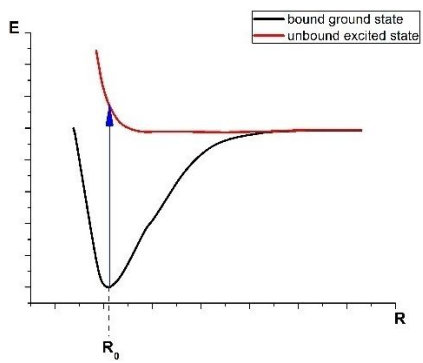

Fig. 1. Photodissociation of diatomic molecules in the unbound excited state.

In this equation, $\chi_{\text {cont }}(R)$ is the nuclear wave function of the molecule for a continuous spectrum, and $\chi_{\text {in }}(R)$ is the nuclear wave function of the molecule for discrete spectrum. The functions $\psi_{f}(r, R)$ and $\psi_{i}(r, R)$ are the electronic wave functions for the electronic states $i$ and $f$ of the molecule, respectively.

For diatomic molecules, when the environment temperature is close to zero (in $\mathrm{K}$ ), the function $\chi_{\text {in }}(R)$ can be considered as the function of a harmonic oscillator for the ground vibrational state, i.e.,

$\chi_{\text {in }}(R)=\left(\frac{m \omega}{\pi}\right)^{1 / 4} \exp \left(-\frac{m \omega}{2}\left(R-R_{0}\right)^{2}\right)$

where $m$ is the reduced mass of a molecule, $\omega$ is the harmonic frequency of molecular vibration at the ground electronic state, and $R_{0}$ is the equilibrium position (or equilibrium bond length) of a molecule. The form of nuclear wave function $\chi_{\text {cont }}(R)$ depends on the decay channel (dissociation channel). We consider the possible decay channels in detail in the next Section.

Previously, we considered the three most probable channels of molecular photodissociation in the framework of the FranckCondon approximation (Valiev et al. 2017): (1) decay (dissociation) in a ground electronic state, (2) decay in a bound excited electronic state, and (3) decay in an unbound excited electronic state. The integral estimation saddle point method was used for the estimation of photolysis cross section for all channels. However, detailed numerical integration showed that $\sigma$ is negligible $\left(\sigma \ll 10^{-41} \mathrm{~cm}^{2}\right)$ for the first two channels of all considered molecules, and therefore we concluded that the considered saddle point method was applied incorrectly, and only the third channel has a large value of $\sigma$. In the present work, the value of $\sigma$ is calculated numerically without any integral estimation. Dissociation in an excited unbound electronic state is illustrated in Fig. 1.

The potential energy curve of the unbound state in Fig. 1 can be represented using the analytical function as $U(R)=$ $A \exp (-B R)$, where $A$ and $B$ are exponential constant parameters. For this case, the vibrational wave function can be written as (Brems 1998)

$\chi(R)=\frac{2}{\pi} \sqrt{\frac{m}{B} \sinh \left(\frac{2 \pi}{B} \sqrt{2 m \varepsilon}\right)} \cdot K_{i \frac{2 \sqrt{2 m \varepsilon}}{B}}\left(\frac{2 \sqrt{2 m A}}{B} \exp \left(-\frac{1}{2} B \cdot R\right)\right)$.

In this equation, $K$ is the Macdonald function and $\varepsilon$ is the energy, which is counted from the predissociation limit. In this case, the $\sigma$ is written as

$\sigma\left(E_{i f}+\varepsilon\right)=\frac{4 \pi^{2}}{3 c}\left(E_{i f}+\varepsilon\right) \cdot\left|d_{\mathrm{e}}^{i f}\left\langle\chi_{\mathrm{con}}(R) \mid \chi_{\mathrm{in}}(R)\right\rangle\right|^{2}$,

where $E_{i f}$ is the dissociation energy of electronic state $f$, and $d_{\mathrm{e}}^{i f}$ is the electric dipole moment for the vertical electronic transition between pure spin electronic states, which is shown in Fig. 1 by an arrow.
Thus, the working formula for the $\sigma$ calculation is obtained for dissociation in the unbound electronic excited state. We note that the other photodissociation channels are possible through the participation of nonadiabatic and spin-orbital coupling interactions effects (Minaev 2007). However, usually the spin-orbital coupling interaction between the excited states is small for light atoms, and therefore the transition moment $\left(d_{\mathrm{e}}^{i f}\right)$ between the spin-mixed states is negligible in the comparison with $d_{\mathrm{e}}^{i f}$ for the pure spin state (Valiev \& Minaev 2016). Also, nonadiabatic effects only play a main role when $d_{\mathrm{e}}^{i f}$ is zero and the Franck-Condon approximation is not valid (Baryshnikov et al. 2015). In the case of alkali oxides, chlorides, and fluorides, heavy atoms are absent, and $d_{\mathrm{e}}^{i f}$ is not zero for any of the considered electronic transitions. Thus, we can conclude that photodissociation in the unbound excited state is the main channel for the considered molecules, and gives the maximum contribution to $\sigma$. Nevertheless, we consider the nonadiabatic effects in photolysis process as well.

In order to calculate $\sigma$ using Eq. (6), we require knowledge about the potential energy curves of diatomic molecules. We used quantum chemical calculations based on current ab initio methods to obtain these values.

\subsection{Computational details}

The potential energy curves of all molecules were obtained using the extended quasi-degenerate perturbation theory of second order (XMC-QDPT2) (Granovsky 2011). The use of this method leads to the calculation of $d_{\mathrm{e}}^{i f}$ for the all considered electronic states. We note that the XMC-QDPT2 method was applied to investigation of electronic and magnetic properties of small and large molecules and led to a good agreement with the experimental measurements (Baryshnikov et al. 2016; Valiev et al. 2013, 2014, 2016; Minaev et al. 2015).

Previously we showed that the photodissociation in the first dissociation limit leads to the largest contribution (90\%) to the rate constant of photolysis due to the solar flux strongly decreasing at the increase of photon frequency (Valiev et al. 2016). Therefore, in this work we only considered potential energy curves corresponding to the first dissociation limit. The details of XMCQDPT2 calculation for each molecule are given below.

The complete active space self-consistent field (CASSCF) was included 7 electrons in 12 molecular orbitals (MOs), 8 electrons in 9 MOs, 8 electrons in $10 \mathrm{MOs}, 7$ electrons in $12 \mathrm{MOs}$, 8 electrons in $12 \mathrm{MOs}, 10$ electrons in 9 MOs, 5 electrons in 13 MOs, 14 electrons in 12 MOs, 16 electrons in 12 MOs, 7 electrons in $10 \mathrm{MOs}, 16$ electrons in $13 \mathrm{MOs}$, and 8 electrons in $8 \mathrm{MOs}$ for $\mathrm{OH}, \mathrm{HF}, \mathrm{HCl}, \mathrm{LiO}, \mathrm{LiF}, \mathrm{LiCl}, \mathrm{NaO}, \mathrm{NaF}$, $\mathrm{NaCl}, \mathrm{KO}, \mathrm{KF}$ and $\mathrm{KCl}$, respectively. The effective Hamiltonian included 30 electronic states. The state averaging was performed on 6 states for $\mathrm{LiO}, \mathrm{NaO}, \mathrm{KO}, 4$ states for hydroxyl, 3 states for the HCL, and 4 states for the rest molecules. The aug-cc-pv5z basis set for HF and aug-cc-pvqz for the other molecules were used. The effective Hamiltonian included 35 states. The quantum chemical calculation was performed using the Firefly software (Granovsky 2012). The numerical calculation of the photolysis cross section via formula (6) was carried out in Mapple 14 (2010).

\section{Results and discussion}

This section presents the results of calculations of dipole moments of electronic transitions, cross sections, and photolysis times, as well as the kinetic energy of decomposition products, 
such as alkali metal atoms, chlorine, fluorine, and oxygen, in the process of photolysis (see Figs. 2-4, and Table A.1). Also, the dependence of the electric dipole transition moments on the internuclear distance around the equilibrium position of the electronic ground state was calculated for all molecules. We calculated this value at two points: 0.05 Angstrom shortward and longward of the equilibrium point of the electronic ground state. According to the discussed calculations, the largest electric dipole transition moment is at the equilibrium point of the electronic ground state. Thus, the Franck-Condon approximation is valid for the consideration of the electronic transition and the calculation of the photolysis cross section for the investigated molecules.

\subsection{Metal oxides and $\mathrm{OH}$}

Potential energies for the ground and several first excited electronic states calculated for the metal oxides $\mathrm{LiO}, \mathrm{NaO}, \mathrm{KO}$, and $\mathrm{OH}$ hydroxide are given in Fig. 2. We note that the ground electronic states for $\mathrm{OH}, \mathrm{LiO}$, and $\mathrm{NaO}$ are two-fold degeneracy and have the symmetry of $X^{2} \Pi$, and for $\mathrm{KO}-X^{2} \Sigma^{+}$.

Figure 2 shows that the lowest excited electronic states for dissociation for all metal oxides $\left(B^{2} \Sigma^{+}\right)$and $\left(B^{2} \Sigma^{-}\right)$for the $\mathrm{OH}$ radical are unbound. We note that the excited state $C^{2} \Pi$ for metal oxides becomes bound owing to the nonadiabatic interaction between it and the ground state $X^{2} \Pi$. The nonadiabatic interaction leads to the repulsion of these potential curves near the internuclear distances 3.7 and $4.1 \AA$ for $\mathrm{LiO}$ and $\mathrm{NaO}$ correspondingly. Unlike the above molecules, the first excited states $A^{2} \Pi$ and $C^{2} \Pi$ of KO molecule have the same symmetry and, as a result, these electronic states are also repulsed owing to the nonadiabatic interaction at the internuclear distance near $5.9 \AA$. For this reason, the electronic state $C^{2} \Pi$ is bound. Thus, we have again only one excited state $B^{2} \Sigma^{-}$, which has to be taken into account to calculate the photolysis rate and lifetime for $\mathrm{LiO}$, $\mathrm{NaO}$, and KO. We also note that the transitions $X^{2} \Pi \rightarrow B^{2} \Sigma^{+}$ and $X^{2} \Sigma^{+} \rightarrow B^{2} \Sigma^{-}$are allowed in accordance with the selection rules (Khalil et al. 2011). However, there is a point of lowest energy of the intersection between bound $A^{2} \Sigma^{-}$and the unbound state $B^{2} \Sigma^{+}$for $\mathrm{OH}$, where nonadiabatic interaction can occur. Therefore the additional $X^{2} \Sigma^{+} \rightarrow A^{2} \Sigma^{+}$channel is considered, too. In this case the absorption occurs from $X^{2} \Sigma^{+}$into $v=2$ of $A^{2} \Sigma^{+}$, where $v$ is a vibrational number. The nonadiabatic interaction between $A^{2} \Sigma^{-}$and $B^{2} \Sigma^{+}$leads to the $B^{2} \Sigma^{+}$decay state. This channel slightly increases the cross section of photolysis $(10 \%)$ due to the transition dipole moment of $X^{2} \Sigma^{+} \rightarrow A^{2} \Sigma^{+}$being smaller than for $X^{2} \Sigma^{+} \rightarrow B^{2} \Sigma^{-}$. We note that there is an intersection point between $A^{2} \Sigma^{-}$and $B^{2} \Sigma^{-}$for $\mathrm{LiO}, \mathrm{NaO}$, and $\mathrm{KO}$ as well. However, the transition dipole moment of $X^{2} \Sigma^{+} \rightarrow A^{2} \Sigma^{+}$ is very small $(0.05 \mathrm{au})$ and this point is located at a significantly higher energy than for the $\mathrm{OH}$ case. Therefore, we can neglect the $X^{2} \Sigma^{+} \rightarrow A^{2} \Sigma^{+}$channel, and $X^{2} \Sigma^{+} \rightarrow B^{2} \Sigma^{-}$is the dominant channel.

\subsection{Chlorides and fluorides of metals and $\mathrm{HCl}, \mathrm{HF}$}

Potential energy curves for the ground state and some lower excited-electronic states of molecules $\mathrm{LiCl}, \mathrm{NaCl}, \mathrm{KCl}, \mathrm{LiF}$, $\mathrm{NaF}, \mathrm{KF}, \mathrm{HCl}$, and $\mathrm{HF}$ are given in Figs. 3 and 4. The ground states of these molecules have the same symmetry $X^{1} \Sigma^{+}$.

It should be noted that for the molecules $\mathrm{LiCl}, \mathrm{NaCl}, \mathrm{KCl}$, $\mathrm{LiF}$, and $\mathrm{NaF}$, the nonadiabatic interaction, as for the molecules considered in Sect. 3.1, is the cause of repulsion of their potential energy curves. As a result, such repulsion of the curves $\left(B^{1} \Sigma^{+}\right.$, $X^{1} \Sigma^{+}$) occurs in the distances of $6.7 \AA, 7.2 \AA$, and $7.8 \AA$, and $20 \AA$ for $\mathrm{LiCl}$ and $\mathrm{LiF}, \mathrm{NaF}$ and $\mathrm{NaCl}$, and $\mathrm{KCl}$, respectively. Finally, there is only one electronic decay state $\left(A^{1} \Pi\right)$ for these molecules and for $\mathrm{HF}, \mathrm{HCl}$. In contrast to molecules considered in this Section, the KF molecule has two excited decay states, $A^{1} \Pi$ and $B^{1} \Sigma^{+}$(Fig. 4d), which both give a contribution to the photolysis rate. We note that there are two possible photolysis channels, $X^{1} \Sigma^{+} \rightarrow A^{1} \Pi$ and $X^{1} \Sigma^{+} \rightarrow B^{1} \Sigma^{+}$, for $\mathrm{LiCl}, \mathrm{NaCl}, \mathrm{KCl}$, $\mathrm{LiF}, \mathrm{NaF}$, and $\mathrm{KF}$. In the case of $X^{1} \Sigma^{+} \rightarrow B^{1} \Sigma^{+}$channel for $\mathrm{LiCl}$, $\mathrm{NaCl}, \mathrm{KCl}, \mathrm{LiF}, \mathrm{NaF}$ the nonadiabatic interaction between $X^{1} \Sigma^{+}$ and $B^{1} \Sigma^{+}$leads to the transition into $X^{1} \Sigma^{+}$state in the dissociation region of $R$. Thus the $X^{1} \Sigma^{+} \rightarrow B^{1} \Sigma^{+}$channel consists of two steps: the electronic transition from $X^{1} \Sigma^{+}$to $B^{1} \Sigma^{+}$and the radiationless electronic transition to $X^{1} \Sigma^{+}$due to the nonadiabatic interaction. The last step is very fast because of the small energy gap between $X^{1} \Sigma^{+}$and $B^{1} \Sigma^{+}$at the repulsive point of $R$ and the strong nonadiabatic interaction between them, as can be seen in Fig. 4. In order to calculate the cross section for this channel, we used the fitting parameters $\left(A\right.$ and $B$ ) for $A^{1} \Pi$ because the potential energy curve of $B^{1} \Sigma^{+}$until the repulsive point, and of $X^{1} \Sigma^{+}$after the repulsive point, are very similar to whole potential energy curve of $A^{1} \Pi$. The transition dipole moment was used for $X^{1} \Sigma^{+} \rightarrow B^{1} \Sigma^{+}$in this case.

We note that the photolysis channel with the emission from $B^{1} \Sigma^{+} \rightarrow A^{1} \Pi$ for $\mathrm{HCl}$ (it is not shown) and HF is also possible. The probability of this channel is dependent on the transition moments of $X^{1} \Sigma^{+} \rightarrow B^{1} \Sigma^{+}$and $B^{1} \Sigma^{+} \rightarrow A^{1} \Pi$. According to the XMC-QDPT2 calculation, this value is 0.000022 au for $B^{1} \Sigma^{+} \rightarrow A^{1} \Pi, 0.000007$ au for $X^{1} \Sigma^{+} \rightarrow B^{1} \Sigma^{+}$of $\mathrm{HCl}, 0.05 \mathrm{au}$ for $B^{1} \Sigma^{+} \rightarrow A^{1} \Pi$, and 0.05 au for HF. Therefore this channel gives the smallest contributions $(\ll 10 \%)$, followed by the $X^{1} \Sigma^{+} \rightarrow A^{1} \Pi$ channel. Thus we neglect it for the estimation of the photolysis lifetime.

\subsection{Cross sections}

The photolysis cross sections versus the wavelength for all considered diatomic molecules are also given in Figs. 2-4. We can see that for each molecule under consideration, the maximum of the photolysis cross section occurs for wavelengths between the initial and final electronic states. The dependence of photolysis cross sections on the wavelength is caused by the dependence of $\varepsilon=E-E_{\text {if }}$ on the wavelength.

\subsection{Photolysis lifetimes}

The photolysis lifetimes $(\tau)$ and photolysis rates $(J)$ were calculated in the framework of the analytical model considered above in Sect. 2.1. According to the analytical model used, the accuracy of obtained photolysis lifetimes depends on the errors of calculation of dipole moments for electronic transitions, characteristics of photolysis cross sections, and dissociation limits. In Table A.1 the dissociation limits and photolysis lifetimes are given together with experimental lifetimes.

As can be seen from Table A.1, the calculated values of dissociation energies for molecules $\mathrm{OH}, \mathrm{LiO}, \mathrm{KO}, \mathrm{HCl}, \mathrm{LiCl}, \mathrm{NaCl}$, $\mathrm{KCl}, \mathrm{HF}, \mathrm{LiF}$, and $\mathrm{NaF}$ are in good agreement with the experimental data (the discrepancies are $\sim 4 \%$ ). For $\mathrm{NaO}$, the deviation between experimental and theoretical values is about $10 \%$ and for $\mathrm{KF}-20 \%$. We note that our calculated values for the dissociation energy for $\mathrm{KO}, \mathrm{LiF}$, and $\mathrm{NaF}$ are in a good agreement with theoretical values of Vasiliu et al. (2010) (the discrepancies are 
R. R. Valiev et al.: Photolysis of diatomic molecules as a source of atoms in planetary exospheres
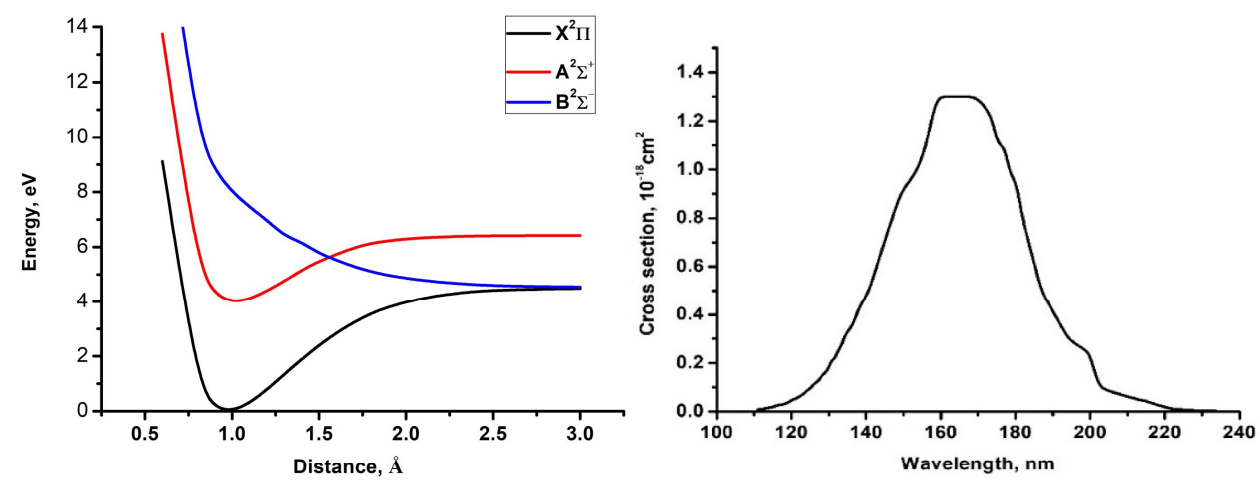

(a)
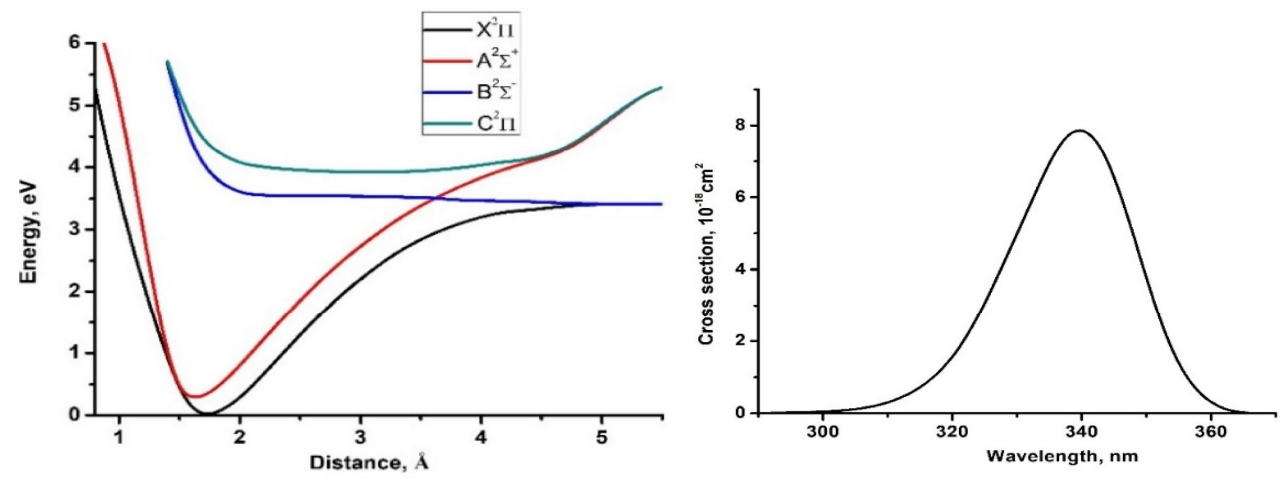

(b)
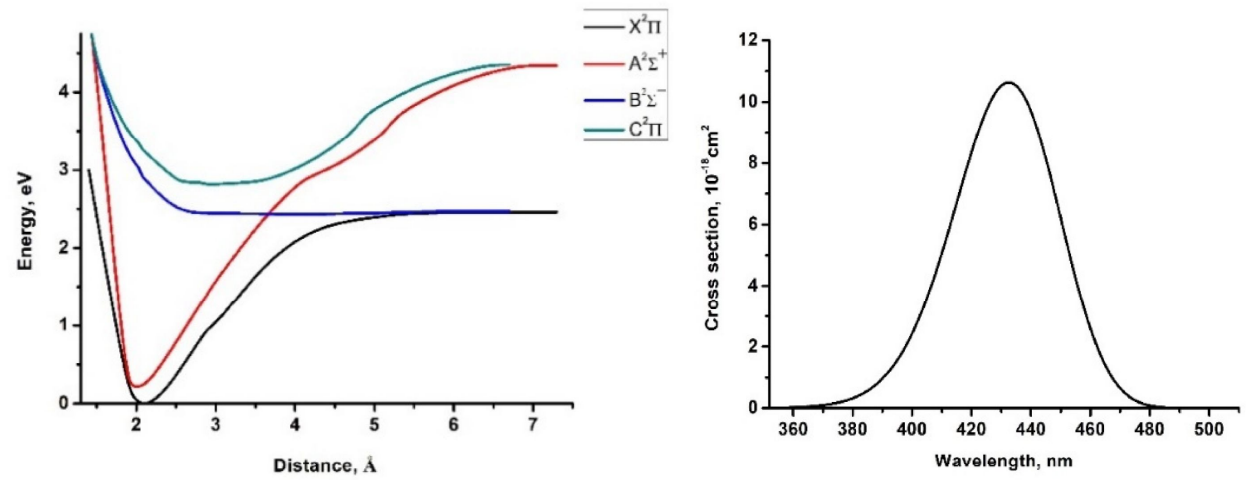

(c)
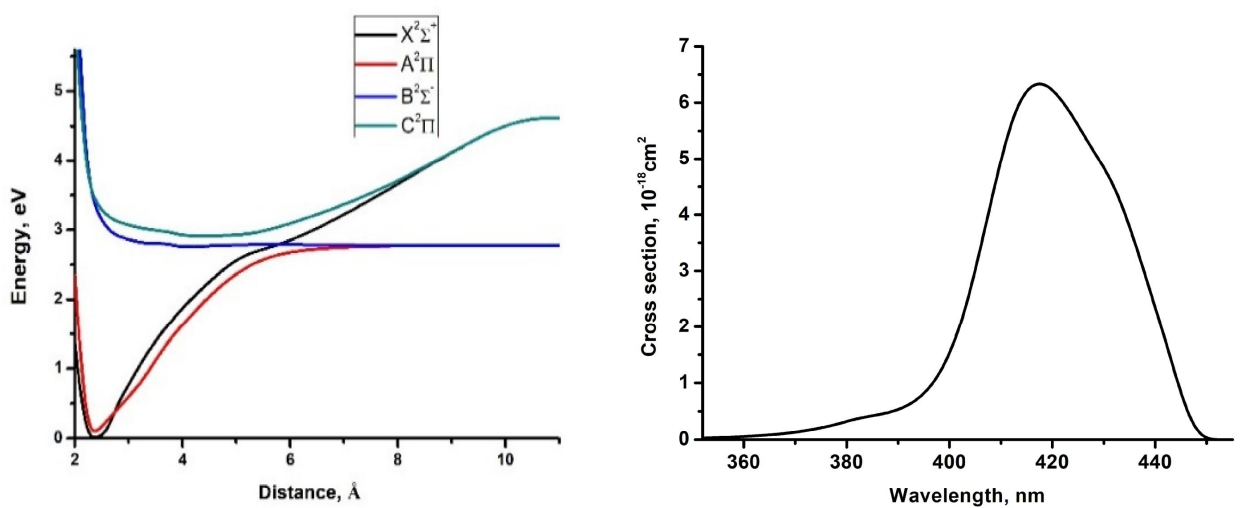

(d)

Fig. 2. Potential energy curves and photolysis cross sections for $\mathrm{OH}(a), \mathrm{LiO}$ $(b), \mathrm{NaO}(c)$, and $\mathrm{KO}(d)$. 

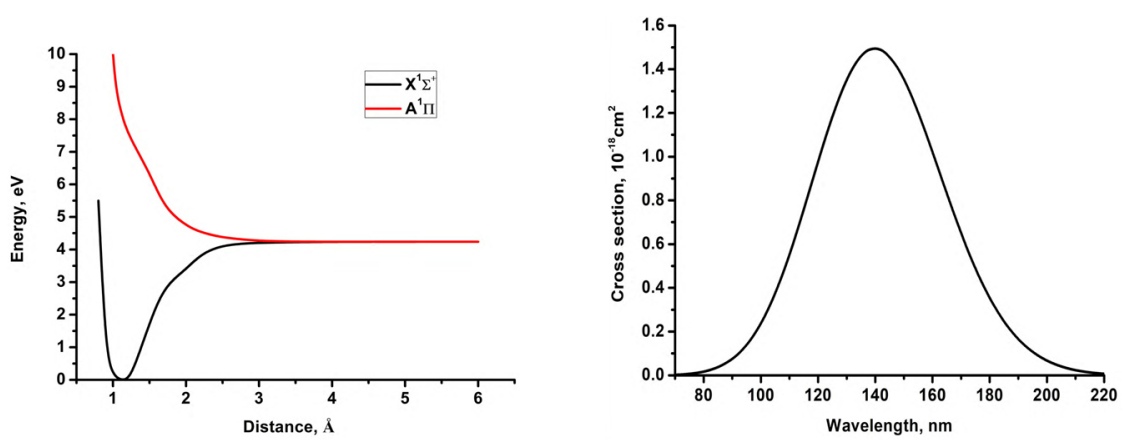

(a)
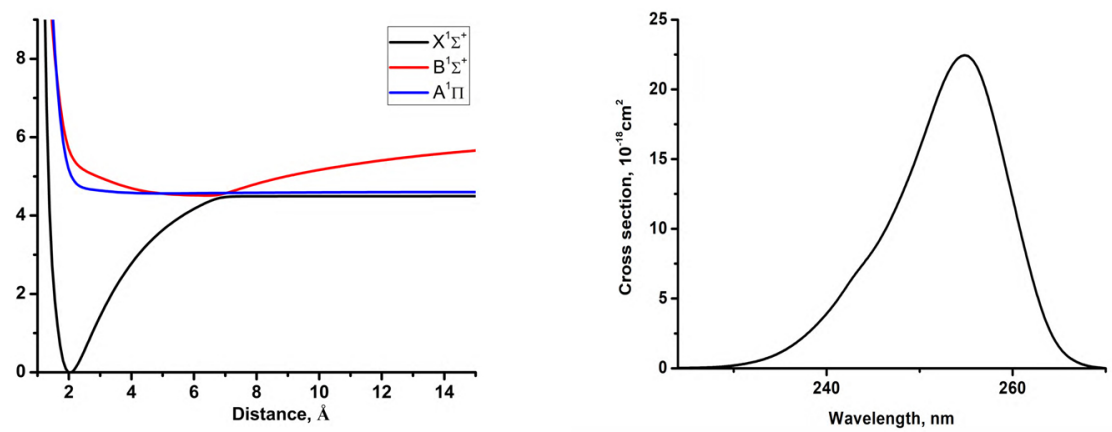

(b)
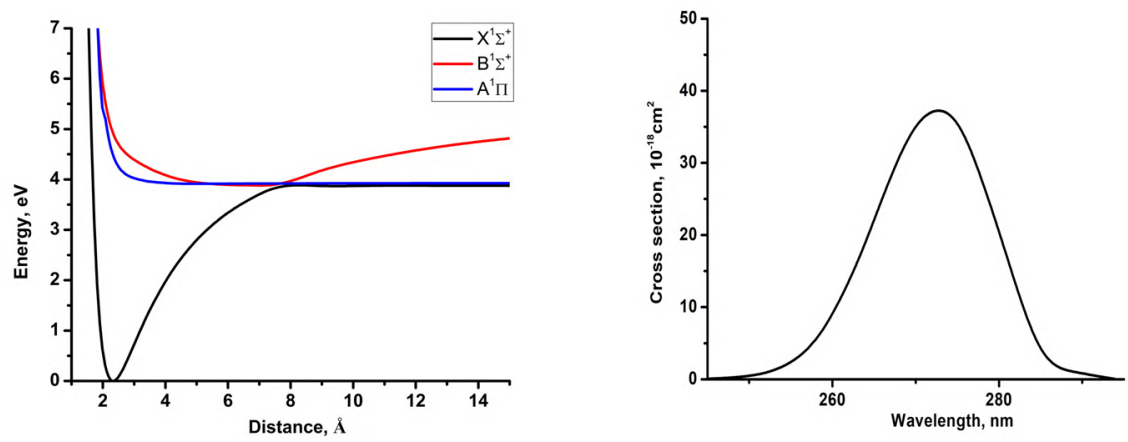

(c)
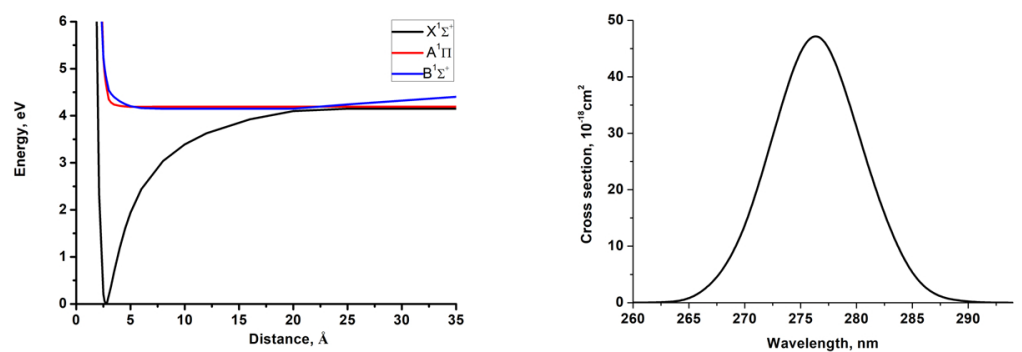

(d)

Fig. 3. Potential energy curves and photolysis cross sections for $\mathrm{HCl}(a), \mathrm{LiCl}(b), \mathrm{NaCl}(c)$, and $\mathrm{KCl}(d)$.

about $3 \%$ ). In contrast, the deviation is increased to $6 \%$ for $\mathrm{LiO}$ and to $10 \%$ for $\mathrm{NaO}$ and $\mathrm{NaCl}$, and up to $18 \%$ for $\mathrm{KF}$. In addition, Table A. 1 shows that for $\mathrm{LiO}, \mathrm{KO}, \mathrm{LiF}$, and $\mathrm{NaF}$ molecules the values of the dissociation energy agree better with the experimental values in comparison with the theoretical values of other authors (Vasiliu et al. 2010). However, the dissociation energies calculated in this work are underestimated by $1 \%$ for $\mathrm{LiCl}, 7 \%$ for $\mathrm{NaCl}$, and $9 \%$ for $\mathrm{NaO}$, and overestimated by $16.8 \%$ for $\mathrm{KF}$ being compared with other theoretical works. Such a large dif- ference is explained by the use (Vasiliu et al. 2010) of the higher basis aug-cc-pwCV5Z for calculation of potential energy curves.

Nevertheless, the theoretical values for photolysis lifetimes for $\mathrm{OH}, \mathrm{HCl}, \mathrm{LiCl}, \mathrm{NaCl}$, and $\mathrm{HF}$ agree with the experimental values within factor of $1.5-2$, while for $\mathrm{KCl}$ and $\mathrm{NaO}$ within a factor of 3 (see Table A.1). For example, the maximal measured photolysis sections for $\mathrm{LiCl}, \mathrm{NaCl}$, and $\mathrm{KCl}$ are $9 \times 10^{-18}, 3.5 \times 10^{-17}$, and $2 \times 10^{-17} \mathrm{~cm}^{-2}$, respectively (Davidovits \& Brodhead 1967), while the theoretical photolysis 
R. R. Valiev et al.: Photolysis of diatomic molecules as a source of atoms in planetary exospheres
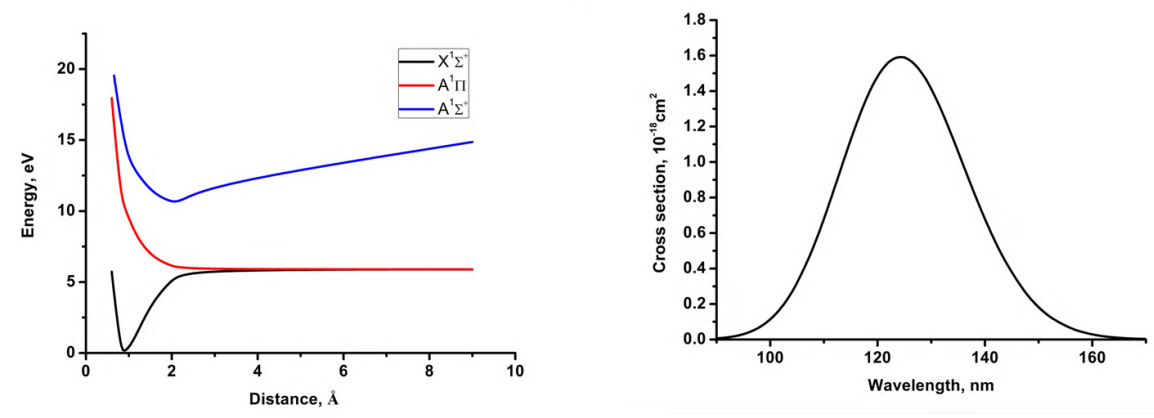

(a)
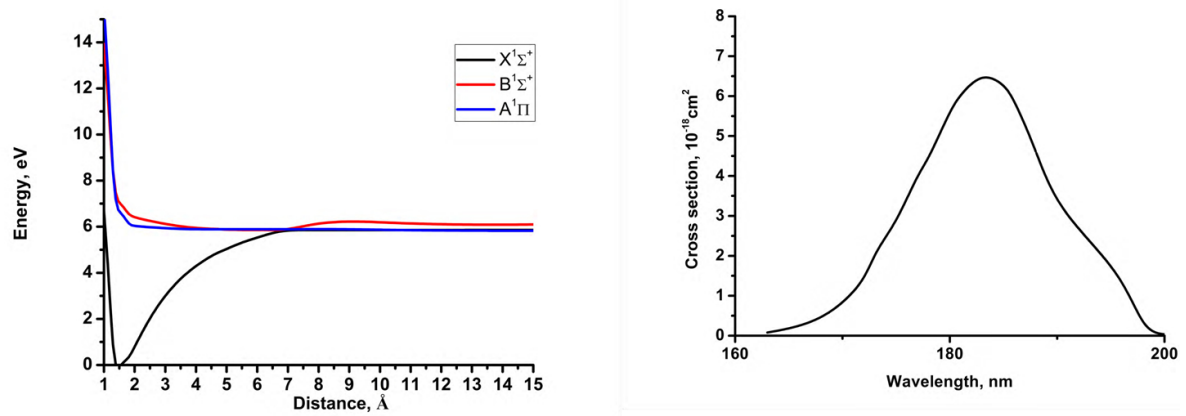

(b)
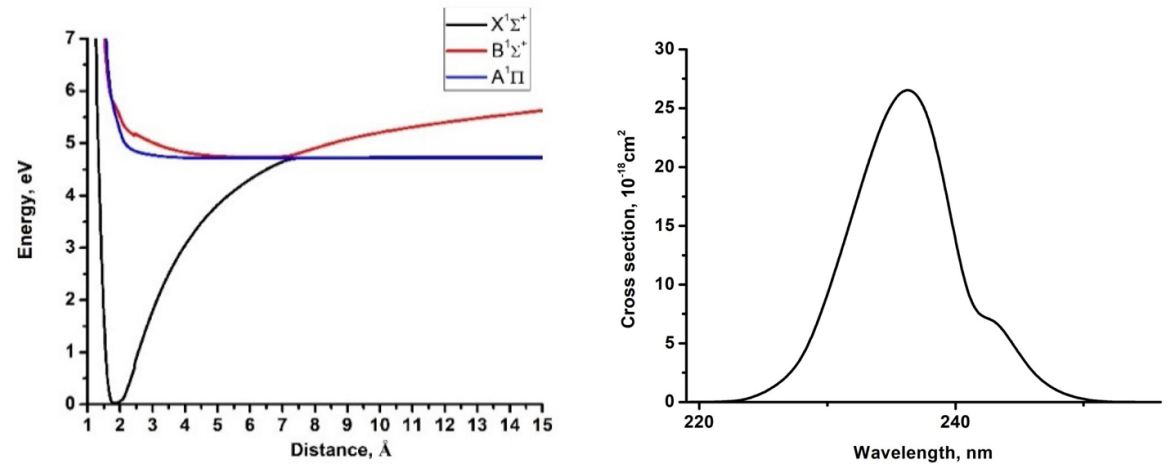

(c)
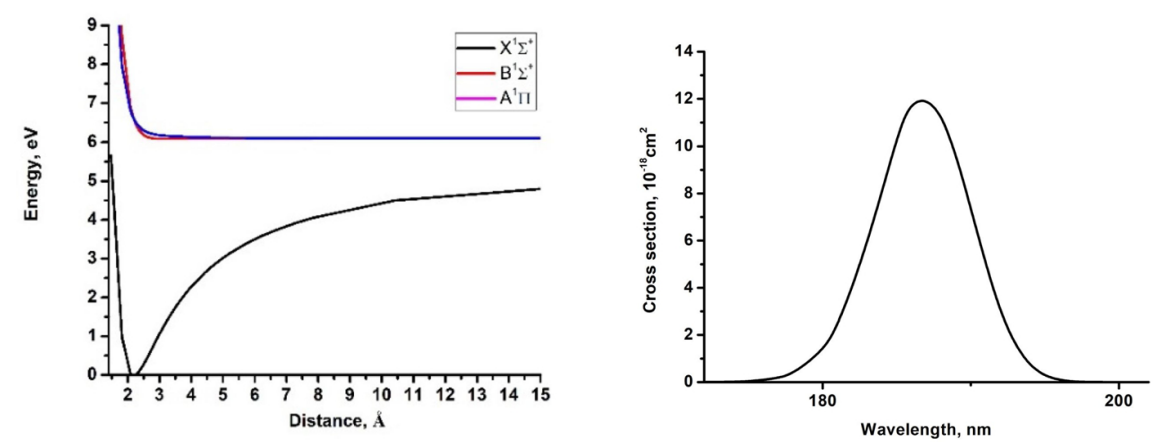

(d)

Fig. 4. Potential energy curves and photolysis cross sections for $\mathrm{HF}(a), \mathrm{LiF}(b), \mathrm{NaF}(c)$, and $\mathrm{KF}(d)$.

cross sections for these species are lower (see Table A.1). One of the reasons for such discrepancies may be caused by different temperature conditions because our calculations were carried out at $0^{\circ} \mathrm{K}$, while the measurements of the $\mathrm{LiCl}, \mathrm{NaCl}$, and $\mathrm{KCl}$ photolysis cross sections (Davidovits \& Brodhead
1967) along with the $\mathrm{NaO}$ photolysis cross section (Self \& Plane 2002) were performed at $1100 \pm 25$ and $200 \mathrm{~K}$, respectively. Our calculated photolysis lifetimes of $\mathrm{LiF}, \mathrm{NaF}$, and $\mathrm{KF}$ are 24, 3, and 60 times longer, respectively, than the photolysis lifetimes estimated by Schaefer \& Fegley (2005) 


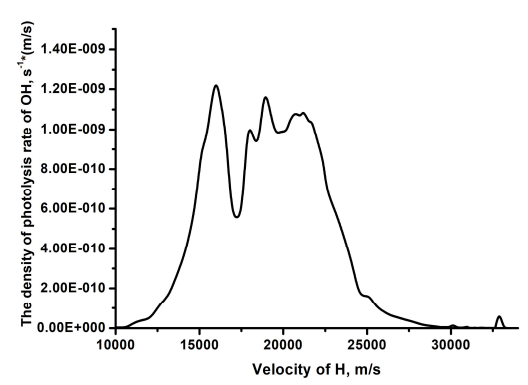

(a)

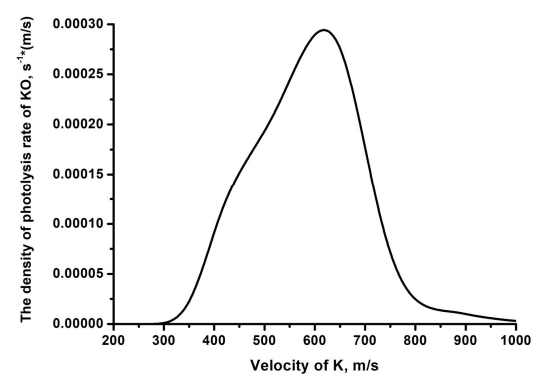

(d)

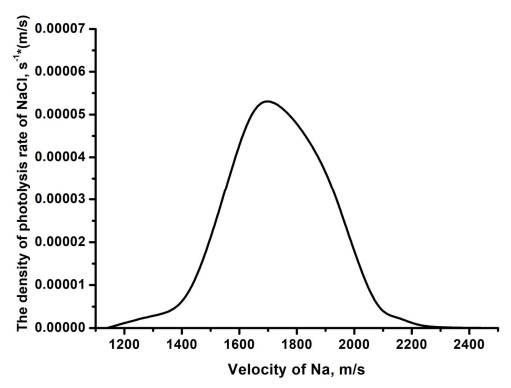

(g)

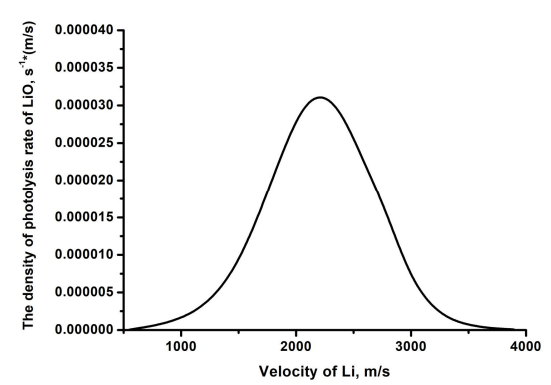

(b)

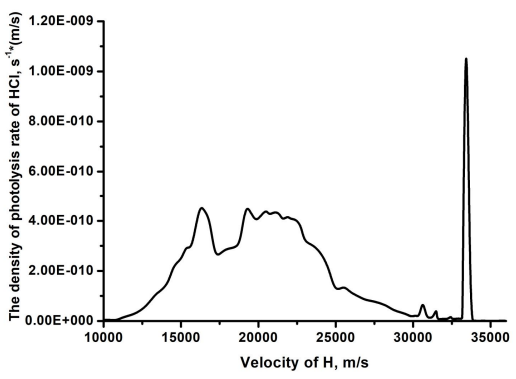

(e)

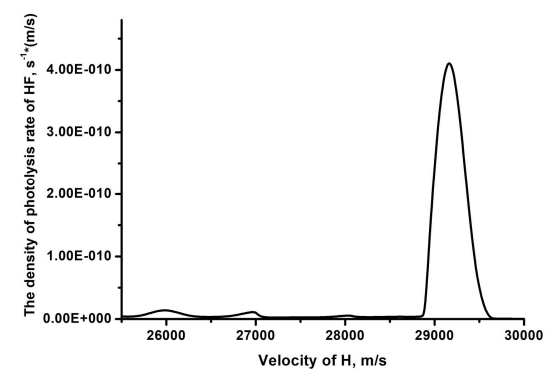

(i)

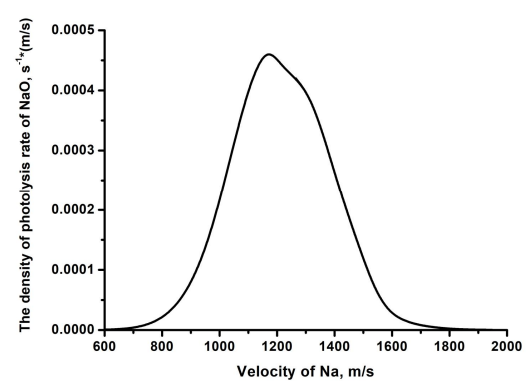

(c)

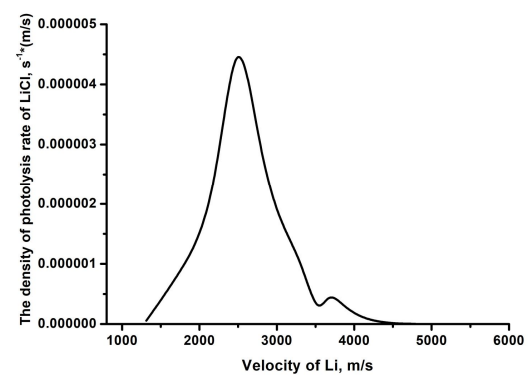

(f)

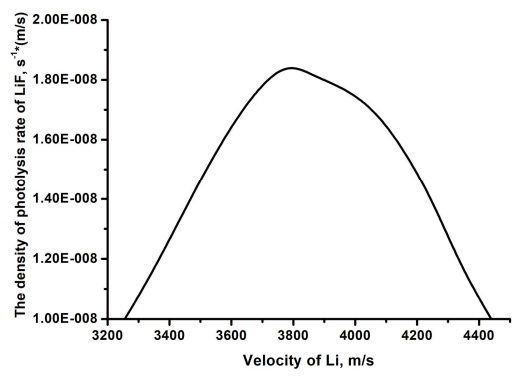

(j)

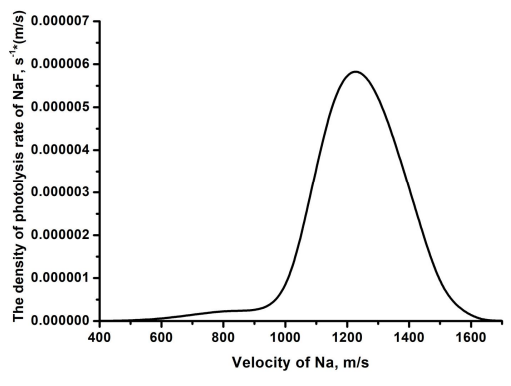

$(\mathrm{k})$

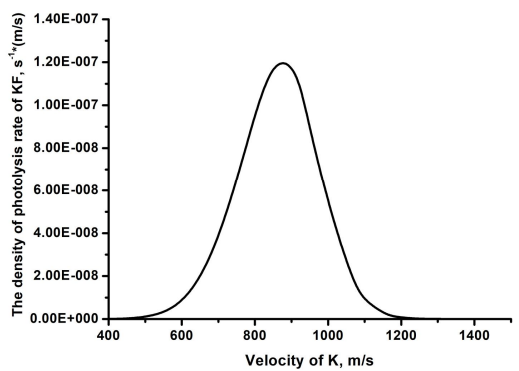

(1)

Fig. 5. Velocity distribution of atoms of alkali metals and hydrogen produced during photolysis of corresponding diatomic molecules: $(a)$ OH; (b) $\mathrm{LiO} ;(c) \mathrm{NaO} ;(d) \mathrm{KO} ;(e) \mathrm{HCl} ;(f) \mathrm{LiCl} ;(g) \mathrm{NaCl} ;(h) \mathrm{KCl} ;(i) \mathrm{HF} ;(j) \mathrm{LiF} ;(k) \mathrm{NaF}$; and $(l) \mathrm{KF}$.

based on trends of photolysis rates and bond energies for the chlorides, bromides, and iodides. However, the estimation of the photolysis lifetime for $\mathrm{LiF}, \mathrm{NaF}$, and $\mathrm{KF}$ was carried out assuming that their unknown $\sigma(\lambda)$ are almost identical to the known $\sigma(\lambda)$ of $\mathrm{LiCl}, \mathrm{NaCl}$, and $\mathrm{KCl}$. According to Table A.1, this approximation is not valid because the values of $\sigma(\lambda)$ are noticeable different for these compounds. Therefore our computed photolysis lifetimes for $\mathrm{LiF}, \mathrm{NaF}$, and $\mathrm{KF}$ are likely to be adequate and predictive.

According to Table A.1, the photolysis lifetimes of LiO, $\mathrm{NaO}, \mathrm{KO}, \mathrm{LiCl}, \mathrm{NaCl}$, and $\mathrm{KCl}$ molecules are less than the typical time of the first ballistic flight in the exospheres of the main atmosphereless bodies of the solar system (Mercury, the Moon, Io, and Europa), which is $\sim 10^{3} \mathrm{~s}$. Therefore, these molecules are 
already dissociated into separate atoms during the first ballistic flight. For other considered molecules, the photolysis lifetimes are comparable or longer than the typical time of a ballistic flight. It means that just a small fraction of these molecules can be destroyed by solar photons during the first ballistic flight in the exospheres of the main atmosphereless bodies of the solar system. Hence, fluorides are minor sources of alkali atoms in planetary exospheres in comparison with oxides and chlorides not only because of the low abundance of fluorine in the solar system, but also because of long photolysis lifetimes of fluorides of alkali metals.

The agreement of the obtained dependence of the photolysis rate on wavelength with other works is more or less reasonable (see Table A.2 and Fig. 5). For the case of $\mathrm{OH}$ photolysis we predict a broad maximum of the photolysis rate at $175-220 \mathrm{~nm}$, while experimental studies (Huebner et al. 1992) and the theoretical work of van Dishoeck \& Dalgarno (1983) of the photolysis reaction $\mathrm{OH}+$ photon $=\mathrm{O}\left({ }^{3} \mathrm{P}\right)+\mathrm{H}$ show a narrower peak at $170-180 \mathrm{~nm}$ and two very narrow peaks near $250 \mathrm{~nm}$. Our theoretical results predict the maximal HF photolysis rate at $121.6 \mathrm{~nm}$. The same maximum is observed in the laboratory (Huebner et al. 1992). We predict higher HF photolysis rates at $130-140 \mathrm{~nm}$ than at $100-110 \mathrm{~nm}$ in agreement with laboratory data (Huebner et al. 1992). The presence of a narrow and strong Lyman alpha peak at $121.6 \mathrm{~nm}$ and the position of calculated broad maximum of $\mathrm{HCl}$ photolysis rate $(170-210 \mathrm{~nm})$ are in agreement with laboratory data (Huebner et al. 1992). Our values of the maximal photolysis cross section of $\mathrm{HCl}$ and the position of the maximal photolysis cross-section peak are comparable to previous theoretical studies of Alexander et al. (1993) (see Table A.1). Our obtained value of the HF maximal photolysis cross section $\left(1.6 \times 10^{-18} \mathrm{~cm}^{-2}\right)$ is two times smaller than that of previous theoretical calculations $\left(3.2 \times 10^{-18} \mathrm{~cm}^{-2}\right.$; Brown \& Balint-Kurti 2000), while the obtained position of the photolysis peak is shifted by about $5 \%$ to shorter wavelengths in comparison with Brown \& Balint-Kurti (2000). The maximal measured photolysis cross sections of $\mathrm{LiCl}, \mathrm{NaCl}$, and $\mathrm{KCl}$ is 235, 240, and $250 \mathrm{~nm}$ (Davidovits \& Brodhead 1967), respectively, while the maximal theoretical photolysis cross sections are shifted to longer wavelengths (see Table A.1), leading to lower velocities of photolysis-generated alkali metal atoms. Thus, our approach allows for estimating the properties of the main photolysis peaks of diatomic molecules qualitatively and, respectively, the velocities of photolysis-generated atoms.

\subsection{Velocities of photolysis-generated atoms of alkali metals and hydrogen}

Comparing the velocity distribution of photolysis-generated atoms of alkali metals and hydrogen (see Fig. 5) with escape velocities from atmosphereless bodies of the solar system (Europa - $2025 \mathrm{~m} \mathrm{~s}^{-1}$, the Moon $-2380 \mathrm{~m} \mathrm{~s}^{-1}$, Io $-2558 \mathrm{~m} \mathrm{~s}^{-1}$, and Mercury $-4250 \mathrm{~m} \mathrm{~s}^{-1}$ ), we can conclude that photolysisgenerated hydrogen atoms escape the gravitational field of the considered bodies upon photolysis of $\mathrm{OH}, \mathrm{HCl}$, and $\mathrm{HF}$. A significant part of photolysis-generated $\mathrm{Li}$ atoms forms after $\mathrm{LiO}$, $\mathrm{LiCl}$, and $\mathrm{LiF}$ photolysis is able to escape Europa, the Moon, and Io, while Mercury captures the majority of such Li atoms. Only a minor fraction of photolysis-generated $\mathrm{Na}$ and $\mathrm{K}$ atoms is able to escape from the Moon, Io, and Europa upon photolysis of corresponding oxides, chlorides, and fluorides. The presence of photolysis-generated metal atoms in planetary exospheres can be confirmed by an analysis of the velocity distribution of exospheric metal atoms (see more detailed discussion of this question in Valiev et al. 2017).

\section{Summary}

A perspective ab initio approach to calculation of the photolysis cross sections of diatomic molecules has been developed. The accuracy of this approach was estimated by comparison with available experimental and theoretical studies of the photolysis of selected diatomic molecules. The developed approach can be used for the calculation of photolysis cross sections and photolysis lifetimes of other diatomic molecules, especially those which are very difficult to study under laboratory conditions.

Acknowledgements. A.A.B. was supported by RFBR grant No. 18-03-00726. C.W. was supported by the Deutsche Forschungsgemeinschaft (DFG, German Research Foundation) RFBR-DFG grant No. WO 1800/7-1. R.R.V. was supported by TU Dortmund University. R.R. Valiev and T. Kurten thank Svenska Kulturfonden, grant number 136102 and Academy of Finland, grant number 1315600 . R.V. is personally thankful to the Tomsk Polytechnic University Competitiveness Enhancement Program (VIU-RSCABS-142/2019).

\section{References}

Acharyya, K., \& Herbst, E. 2017, ApJ, 850, 105

Agúndez, M., Fonfría, J. P., Cernicharo, J., et al. 2012, A\&A, 543, A48 Alexander, M. H., Pouilly, B., \& Duhoo, T. 1993, J. Chem. Phys., 99, 1752

Barton, E. J., Chiu, C., Golpayegani, S., et al. 2014, MNRAS, 442, 1821

Baryshnikov, G. V., Valiev, R. R., Karaush, N. N., Minaev, B. F., \& Agren, H. 2015, Chem. Phys., 459, 65

Baryshnikov, G. V., Valiev, R. R., Karaush, N. N., et al. 2016, Phys. Chem. Chem. Phys., 18, 28040

Berezhnoy, A. A., \& Klumov, B. A. 2008, Icarus, 195, 511

Berezhnoy, A. A. 2010, Adv. Space Rev., 45, 70

Berezhnoy, A. A. 2013, Icarus, 226, 205

Berezhnoy, A. A. 2018, Icarus, 300, 200

Bida, Th. A., \& Killen, R. M. 2017, Icarus, 289, 227

Bittner, D. M., \& Bernath, P. F. 2018, ApJS, 235, 8

Brems, V. 1998, Chem. Phys., 238, 85

Brown, M. E., \& Hill, R. E. 1996, Nature, 380, 229

Brown, A., \& Balint-Kurti, R. E. 2000, J. Chem. Phys., 113, 1870

Bulewicz, E. M., Phillips, L. E., \& Sugden, T. M. 1961, Trans. Faraday Soc., 57, 921

Cassidy, T. A., Merkel, A. W., Burger, M. H., et al. 2015, Icarus, 248, 547

Colaprete, A. 2016, Science, 351, 249

Davidovits, P., \& Brodhead, D. C. 1967, J. Chem. Phys., 46, 2968

De Keyser, J., Dhooghe, F., Altwegg, K., et al. 2017, MNRAS, 469, S695

Dhooghe, F., De Keyser, J., Altwegg, K., et al. 2017, MNRAS, 472, 1336

Duhoo, T., \& Pouilly, B. 1995, J. Chem. Phys., 103, 182

Engin, S., Sisourat, N., \& Carniato, S. 2012, J. Chem. Phys., 137, 154304

Evans, L. G., Peplowski, P. N., McCubbin, F. M., et al. 2015, Icarus, 257, 417

Granovsky, A. A. 2011, J. Chem. Phys., 134, 214113

Granovsky, A. A. 2012, Firefly, vol 8.0.0, http://classic.chem.msu.su/ gran/firefly/index.html

Grava, C., Schneider, N. M., Leblanc, F., et al. 2014, J. Geophys. Res. Planets, 119,404

Grumpe, A., Wöhler, C., Berezhnoy, A. A., \& Shevchenko, V. V. 2019, Icarus, 321,486

Heays, A. N., Bosman, A. D., \& van Dishoeck, E. F. 2017, A\&A, 602, A105

Herzberg, G. 1989, Molecular Spectra and Molecular Structure: Spectra of Diatomic Molecules (Malabar, USA: Krieger Pub Co.), 660

Huber, K. P., \& Herzberg, G. 1979, Molecular Spectra and Molecular Structure. IV. Constants of Diatomic Molecules (New York: Van Nostrand Reinhold Co.), 716

Huebner, W. F., Keady, J. J., \& Lyon, S. P. 1992, Astrophys. Space Sci., 195, 291 Huebner, W. F., \& Mukherjee, J. 2015, Planet. Space Sci., 106, 11

Hynes, A. J., Steinberg, M., \& Schofield, K. J. 1984, Chem. Phys., 80, 2585 Indriolo, N., Neufeld, D. A., Seifahrt, A., \& Richter, M. J. 2013, ApJ, 764, 188 Johns, J. W. C., \& Barrow, R. F. 1959, Proc. R. Soc. London Ser. A, 251, 504 Khalil, H., Brites, V., Quéré, F. L., \& Léonard, C. 2011, Chem. Phys., 386, 50 Lambert, H. M., Dagdigian, P. J., \& Alexander, M. H. 1998, J. Chem. Phys., 108, 4460

Langhoff, S. R., Bauschlicher, C. W., \& Partridge, H. 1986, J. Chem. Phys., 84, 4474 
Langhoff, S. R., Partridge, H., \& Bauschlicher, Ch. W. 1991, Chem. Phys., 153, 1

Lee, S. 1995, J. Chem. Phys., 103, 3501

Li, Y.-J., Zhang, P.-Y., \& Han, K.-L. 2010, J. At. Mol. Sci., 1, 18

Litvak, M. L., \& Sanin, A. B. 2018, Physics-Uspekhi, 61, 779

Lodders, K. 1999, ApJ, 519, 793

Mapple 14 2010, (Waterloo Maple Inc.), https: //www . maplesoft. com

Mbarek, R., \& Kempton, E. M.-R. 2016, ApJ, 827, 121

Minaev, B. F. 2007, Russ. Chem. Rev., 76, 1059

Minaev, B. F., Valiev, R. R., Nikonova, E. N., et al. 2015, J. Phys. Chem. A, 119 1948

Mendillo, M., Laurent, S., Wilson, J., et al. 2007, Nature, 448, 330

Monje, R. R., Lis, D. C., Roueff, E., et al. 2013, ApJ, 767, 81

Moses, J. I., Zolotov, M. Yu., \& Fegley, Jr., Br. 2002, Icarus, 156, 107

Moullet, A., Lellouch, E., Moreno, R., et al. 2013, ApJ, 776, 32

Nee, J. B., Suto, M., \& Lee, L. C. 1985, J. Phys. B: At. Mol. Phys., 18, L293

Regan, P. M., Ascenzi, D., Brown, A., Balint-Kurti, G. G., \& Orr-Ewing, A. J. 2000, J. Chem. Phys., 112, 10259

Renggli, C. J., King, P. L., Henley, R. W., \& Norman, M. D. 2017, Geochim. Cosmochim. Acta, 206, 296

Riess, I. 1972, J. Chem. Phys., 56, 1613

Sandor, B. J., \& Clancy, R. T. 2012, Icarus, 220, 618

Schaefer, L., \& Fegley, Jr., Br. 2005, Icarus, 173, 454

Self, D. E., \& Plane, J. M. C. 2002, Phys. Chem. Chem. Phys., 4, 16
Silver, J. A., Worsnop, D. R., Freedman, A., \& Kolb, C. E. 1986, J. Chem. Phys., 84, 4378

Steinberg, M., \& Schofield, K. 1991, J. Chem. Phys., 94, 3901

van Dishoeck, E. F., \& Dalgarno, A. 1983, J. Chem. Phys., 79, 873

van Dishoeck, E. F., van Hemert, M. C., \& Dalgarno, A. 1982, J. Chem. Phys., 77,3693

van Dishoeck, E. F., van Hemert, M. C., Allison, A., \& Dalgarno, A. 1984, J. Chem. Phys., 81, 5709

Valiev, R. R., \& Minaev, B. F. 2016, J. Mol. Model., 22, 214

Valiev, R. R., Telminov, E. N., Solodova, T. A., et al. 2013, Chem. Phys. Lett., 588,184

Valiev, R. R., Telminov, E. N., Solodova, T. A., et al. 2014, Spectrochim. Acta A, 128, 137

Valiev, R. R., Berezhnoy, A. A., Minaev, B. F., Chernov, V. E., \& Cherepanov, V. N. 2016, Russ. Phys. J., 59, 536

Valiev, R. R., Berezhnoy, A. A., Sidorenko, A. D., Merzlikin, B. S., \& Cherepanov, V. N. 2017, Planet. Space Sci., 145, 38

Vasiliu, M., Li, S., Peterson, K. A., Feller, D., Gole, J. L., \& Dixon, D. A. 2010, J. Phys. Chem. A, 114, 4272

Vedeneyev, V. I., Gurvich, L. V., Kondratyev, V. N., Medvedev, V. A., \& Frankevich, Ye. L. 1966, Bond Energies, Ionization Potentials, and Electron Affinities (New York: St. Martin's Press), 202

Wan, M.-J., Huang, D.-H., Yang, J.-S., et al. 2015, Mol. Phys., 113, 1359 
R. R. Valiev et al.: Photolysis of diatomic molecules as a source of atoms in planetary exospheres

\section{Appendix A: Tables}

Table A.1. Dipole moment of transition, dissociation energy, cross section, and photolysis lifetime of diatomic molecules.

\begin{tabular}{|c|c|c|c|c|c|c|}
\hline Molecule & Channel & $\begin{array}{l}\text { Dipole moment } \\
\text { of transition, } u\end{array}$ & $\begin{array}{l}\text { Dissociation } \\
\text { energy, eV }\end{array}$ & $\begin{array}{l}\text { Maximal photolysis } \\
\text { cross section, } \mathrm{cm}^{2} \\
\text { (corresponding } \\
\text { wavelength, } \mathrm{nm} \text { ) }\end{array}$ & $\begin{array}{l}\text { Photolysis lifetime } \\
\text { at } 1 \text { au, s metal }\end{array}$ & $\begin{array}{l}\text { Peaks of speed of } \\
\text { photolysis-generated } \\
\text { and } \mathrm{H} \text { atoms, } \mathrm{m} \mathrm{s}^{-1}\end{array}$ \\
\hline $\mathrm{OH}$ & $\begin{array}{l}X^{2} \Pi \rightarrow B^{2} \Sigma^{+} \\
X^{2} \Pi \rightarrow A^{2} \Sigma^{-}\end{array}$ & $\begin{array}{l}0.35 \text { (1st } \\
\text { channel) } 0.15 \\
(2 \text { nd channel })\end{array}$ & $\begin{array}{l}4.45 \\
4.4 \pm 0.01^{(g)}\end{array}$ & $\begin{array}{l}1.4 \times 10^{-18}(163.9) \\
(3.39 \pm 0.22) \times 10^{-18(g)}\end{array}$ & $\begin{array}{l}2.0 \times 10^{5} \\
1.34 \times 10^{5(h)} \\
4.9 \underset{(\text { theor) }}{4 \times 10^{4}(h)}\end{array}$ & $18500 \pm 3000$ \\
\hline $\mathrm{LiO}$ & $X^{2} \Pi \rightarrow B^{2} \Sigma^{-}$ & 0.34 & $\begin{array}{l}3.40 \\
3.65^{(a)} ; \\
3.41^{(n)} ; 3.41^{(j)} \\
3.39^{(j)} 0.22^{(g)}\end{array}$ & $8 \times 10^{-18}(337.5)$ & $\begin{array}{l}28 \\
5^{(i)} ; 140^{(j)} ; 170^{(k)}\end{array}$ & $2200 \pm 500$ \\
\hline $\mathrm{NaO}$ & $X^{2} \Pi \rightarrow B^{2} \Sigma^{-}$ & 0.5 & $\begin{array}{l}2.46 \\
2.73^{(a)} ; 2.62^{(n)} ; \\
2.46^{(j)} \\
2.80 \pm 0.04^{(c)}\end{array}$ & $\begin{array}{l}10.78 \times 10^{-18} \\
(432.5)\end{array}$ & $\begin{array}{l}5 \\
3^{(i)} ; 60^{(j)} 70^{(k)} ; 18^{(l)}\end{array}$ & $1200 \pm 200$ \\
\hline KO & $X^{2} \Sigma^{+} \rightarrow B^{2} \Sigma^{-}$ & 0.3 & $\begin{array}{l}2.77 \\
2.85^{(a)} ; 2.78^{(j)} \\
2.82 \pm 0.13^{(b)}\end{array}$ & $6.5 \times 10^{-18}(417.5)$ & $\begin{array}{l}14 \\
60^{(i)} ; 30^{(j)} 70^{(k)}\end{array}$ & $600 \pm 150$ \\
\hline $\mathrm{HCl}$ & $X^{1} \Sigma^{+} \rightarrow A^{1} \Pi$ & 0.5 & $\begin{array}{l}4.29 \\
4.44 \pm 0.02^{(g)}\end{array}$ & $\begin{array}{l}1.49 \times 10^{-18}(140) \\
4.5 \times 10^{-18}(150)^{(o)}\end{array}$ & $\begin{array}{l}2.1 \times 10^{5} \\
1.4 \times 10^{5(h)}\end{array}$ & $\begin{array}{l}20000 \pm 5000 \\
33500 \pm 200\end{array}$ \\
\hline $\mathrm{LiCl}$ & $\begin{array}{l}X^{1} \Sigma^{+} \rightarrow A^{1} \Pi \\
X^{1} \Sigma^{+} \rightarrow B^{1} \Sigma^{+}\end{array}$ & $\begin{array}{l}0.29 \text { (1st } \\
\text { channel); } 0.58 \\
\text { (2nd channel) }\end{array}$ & $\begin{array}{l}4.66 \\
4.88^{(a)} \\
4.80 \pm 0.13^{(d)}\end{array}$ & $23 \times 10^{-18}(256)$ & $\begin{array}{l}225 \\
480^{(m)}\end{array}$ & $2500 \pm 600$ \\
\hline $\mathrm{NaCl}$ & $\begin{array}{l}X^{1} \Sigma^{+} \rightarrow A^{1} \Pi \\
X^{1} \Sigma^{+} \rightarrow B^{1} \Sigma^{+}\end{array}$ & $\begin{array}{l}0.25 \text { (1st } \\
\text { channel); } 1.00 \\
\text { (2nd channel) }\end{array}$ & $\begin{array}{l}3.92 \\
4.22^{(a)} \\
4.26 \pm 0.02^{(g)}\end{array}$ & $38 \times 10^{-18}(274)$ & $\begin{array}{l}42 \\
60^{(m)}\end{array}$ & $1700 \pm 200$ \\
\hline $\mathrm{KCl}$ & $\begin{array}{l}X^{1} \Sigma^{+} \rightarrow A^{1} \Pi \\
X^{1} \Sigma^{+} \rightarrow B^{1} \Sigma^{+}\end{array}$ & $\begin{array}{l}0.25 \text { (1st } \\
\text { channel); } 0.77 \\
\text { (2nd channel) }\end{array}$ & $\begin{array}{l}4.14 \\
4.39^{(a)} ; \\
4.4 \pm 0.02^{(g)}\end{array}$ & $53 \times 10^{-18}(277)$ & $\begin{array}{l}52 \\
140^{(m)}\end{array}$ & $850 \pm 100$ \\
\hline $\mathrm{HF}$ & $X^{1} \Sigma^{+} \rightarrow B^{1} \Pi$ & 0.50 & $\begin{array}{l}5.88 \\
5.87 \pm 0.01^{(f)}\end{array}$ & $\begin{array}{l}1.6 \times 10^{-18}(125) ;(120)^{(p)} \\
3.2 \times 10^{-18}(122)^{(q)} \\
3.5 \times 10^{-18}(118)^{(r)}\end{array}$ & $\begin{array}{l}2 \times 10^{6} \\
6.3 \times 10^{6(h)}\end{array}$ & $29300 \pm 300$ \\
\hline $\mathrm{LiF}$ & $\begin{array}{l}X^{1} \Sigma^{+} \rightarrow A^{1} \Pi \\
X^{1} \Sigma^{+} \rightarrow B^{1} \Sigma^{+}\end{array}$ & $\begin{array}{l}0.29 \text { (1st } \\
\text { channel); } 0.25 \\
\text { (2nd channel) }\end{array}$ & $\begin{array}{l}6.02 \\
5.94^{(a)} \\
5.91 \pm 0.34^{(e)}\end{array}$ & $6.6 \times 10^{-18}(183)$ & $\begin{array}{l}35400 \\
1500^{(m)}\end{array}$ & $3760 \pm 500$ \\
\hline $\mathrm{NaF}$ & $\begin{array}{l}X^{1} \Sigma^{+} \rightarrow A^{1} \Pi \\
X^{1} \Sigma^{+} \rightarrow B^{1} \Sigma^{+}\end{array}$ & $\begin{array}{l}0.25 \text { (1st } \\
\text { channel); } 0.67 \\
\text { (2nd channel) }\end{array}$ & $\begin{array}{l}4.82 \\
4.94^{(a)} \\
4.96 \pm 0.30^{(e)}\end{array}$ & $27 \times 10^{-18}(235)$ & $\begin{array}{l}486 \\
160^{(m)}\end{array}$ & $1263 \pm 200$ \\
\hline $\mathrm{KF}$ & $\begin{array}{l}X^{1} \Sigma^{+} \rightarrow B^{1} \Sigma^{+} \\
X^{1} \Sigma^{+} \rightarrow A^{1} \Pi\end{array}$ & $\begin{array}{l}0.36 \text { (1st } \\
\text { channel); } 0.21 \\
\text { (2nd channel) }\end{array}$ & $\begin{array}{l}6.19 \\
5.11^{(a)} \\
5.12 \pm 0.05^{(g)}\end{array}$ & $12 \times 10^{-18}(188)$ & $\begin{array}{l}30400 \\
500^{(m)}\end{array}$ & $844 \pm 100$ \\
\hline
\end{tabular}

Notes. ${ }^{(a)}$ Theoretical calculations from the work of Vasiliu et al. (2010). ${ }^{(b)}$ Experimental value, taken from Hynes et al. (1984). ${ }^{(c)}$ Experimental value, taken from Steinberg \& Schofield (1991). ${ }^{(d)}$ Experimental value, taken from Bulewicz et al. (1961). ${ }^{(e)}$ Experimental value, taken from Huber \& Herzberg (1979). ${ }^{(f)}$ Experimental value, taken from Johns \& Barrow (1959). ${ }^{(g)}$ Experimental value, taken from Vedeneyev et al. (1966). ${ }^{(h)}$ Huebner \& Mukherjee (2015). Symbols (theor) and (exp) refer to theoretical and experimental cross-section data, respectively. ${ }^{(i)}$ Valiev et al. (2017). ${ }^{(j)}$ Valiev et al. (2016). ${ }^{(k)}$ Berezhnoy (2013). ${ }^{(l)}$ Experimental value at $200 \mathrm{~K}$ (Self \& Plane 2002). ${ }^{(m)}$ Schaefer \& Fegley (2005) based on experimental photolysis cross sections of Davidovits \& Brodhead (1967). ${ }^{(n)}$ Theoretical value of Langhoff et al. $(1991) .{ }^{(o)}$ Theoretical values of $\mathrm{HCl}$ photolysis cross sections (Alexander et al. 1993). ${ }^{\left({ }^{p}\right)}$ Theoretical values of HF photolysis cross sections (Brown \& Balint-Kurti 2000). ${ }^{(q)} \mathrm{Li}$ et al. (2010). ${ }^{(r)}$ Experimental value, taken from Nee et al. (1985). 
Table A.2. Properties of photolysis of studied diatomic molecules for quiet Sun.

\begin{tabular}{|c|c|c|c|c|c|c|}
\hline Molecule & $\begin{array}{l}\text { Wavelength of } \\
\text { maximal photolysis } \\
\text { cross section, nm } \\
\text { (this work) }\end{array}$ & $\begin{array}{l}\text { Half-width of peak } \\
\text { of maximal photoly- } \\
\text { sis cross section, nm } \\
\text { (this work) }\end{array}$ & $\begin{array}{l}\text { Wavelength of maximal } \\
\text { photolysis cross section, } \mathrm{nm} \\
\text { (other works) }\end{array}$ & $\begin{array}{l}\text { Half-width of peak } \\
\text { of maximal photoly- } \\
\text { sis cross section, nm } \\
\text { (other works) }\end{array}$ & $\begin{array}{l}\text { Typical energy of } \\
\text { photolysis-produced } \\
\text { metal atoms and H, } \\
\text { eV (this work) }\end{array}$ & $\begin{array}{l}\text { Typical energy of } \\
\text { photolysis-produced } \\
\text { metal atoms and } \mathrm{H}, \\
\mathrm{eV} \text { (other works) }\end{array}$ \\
\hline $\mathrm{OH}$ & 163.9 & 40 & $\operatorname{(theor)}^{160} ; \underset{(\exp )}{170}$ & ${\underset{\text { (theor) }}{ }}^{(h)} ;{\underset{(\exp )}{30}}^{(b)}$ & $2.9 \pm 0.7$ & ${ }_{\text {(theor) }}^{1.19^{(a)}} ; \underset{(\exp )}{1.88^{(a)}}$ \\
\hline $\mathrm{LiO}$ & 337.5 & 25 & $353^{(c)}$ & $12^{(c)}$ & $0.18 \pm 0.09$ & $0.07^{(c)} ; 1.3^{(d)}$ \\
\hline $\mathrm{NaO}$ & 432.5 & 30 & $490^{(c)}$ & $20^{(c)}$ & $0.17 \pm 0.06$ & $0.03^{(c)} ; 0.4^{(c)}$ \\
\hline KO & 417.5 & 35 & 282 & $20^{(c)}$ & $0.06 \pm 0.02$ & $0.47^{(c)} ; 0.35^{(e)}$ \\
\hline $\mathrm{HF}$ & 125 & 30 & $120^{(i)} ; 121.6^{(k)}, 118^{(l)}$ & $60^{(b)} ; 20^{(i)}, 13^{(l)}$ & $2.8 \pm 0.7$ & $4.38^{(a)}$ \\
\hline $\mathrm{LiF}$ & 183 & 15 & $118^{(l)}$ & $13^{(l)}$ & $0.55 \pm 0.2$ & \\
\hline $\mathrm{NaF}$ & 235 & 11 & & & $0.25 \pm 0.05$ & \\
\hline KF & 188 & 9 & & & $0.16 \pm 0.05$ & \\
\hline $\mathrm{HCl}$ & 140 & 55 & $170^{(b)} ; 150^{(j)}$ & $50^{(b)} ; 30^{(j)}$ & $4.1 \pm 1.1$ & $4.29^{(a)}$ \\
\hline $\mathrm{LiCl}$ & 256 & 15 & $232^{(f)}$ & $30^{(f)}$ & $0.3 \pm 0.1$ & \\
\hline $\mathrm{NaCl}$ & 274 & 20 & $240^{(f)} ; 237^{(g)} ; 259^{(g)}$ & $30^{(f)} ; 6^{(g)} ; 12^{(g)}$ & $0.4 \pm 0.1$ & \\
\hline $\mathrm{KCl}$ & 277 & 9 & $250^{(f)}$ & $20^{(f)}$ & $0.16 \pm 0.04$ & \\
\hline
\end{tabular}

Notes. ${ }^{(a)}$ Huebner \& Mukherjee (2015). ${ }^{(b)}$ Huebner et al. (1992) (in this paper dependences of photolysis rate (not photolysis cross section) on wavelength were presented) and Regan et al. (2000). ${ }^{(c)}$ Valiev et al. (2017) (only parameters of the channel with maximal photolysis rate are given). ${ }^{(d)}$ Berezhnoy (2013). ${ }^{(e)}$ Berezhnoy (2010). ${ }^{(f)}$ Davidovits \& Brodhead (1967). ${ }^{(g)}$ Silver et al. (1986). ${ }^{(h)}$ van Dishoeck \& Dalgarno (1983). ${ }^{(i)}$ Brown \& Balint-Kurti (2000). ${ }^{(j)}$ Alexander et al. (1993). ${ }^{(k)}$ Regan et al. (2000). ${ }^{\left({ }^{(}\right)}$Nee et al. (1985). Values of (theor) and (exp) refer to theoretical and experimental cross-section data, respectively. 